\title{
A Customer's View on Key Aspects of Metal AdDitive ManUfaCtURing
}

\author{
Martin Nozar, Ivana Zetková, Pavel Hanzl \& Milan Daňa
}

Regional Technological Institute, University of West Bohemia - Faculty of Mechanical Engineering, Univerzitní 8, 30614 Pilsen, Czech Republic
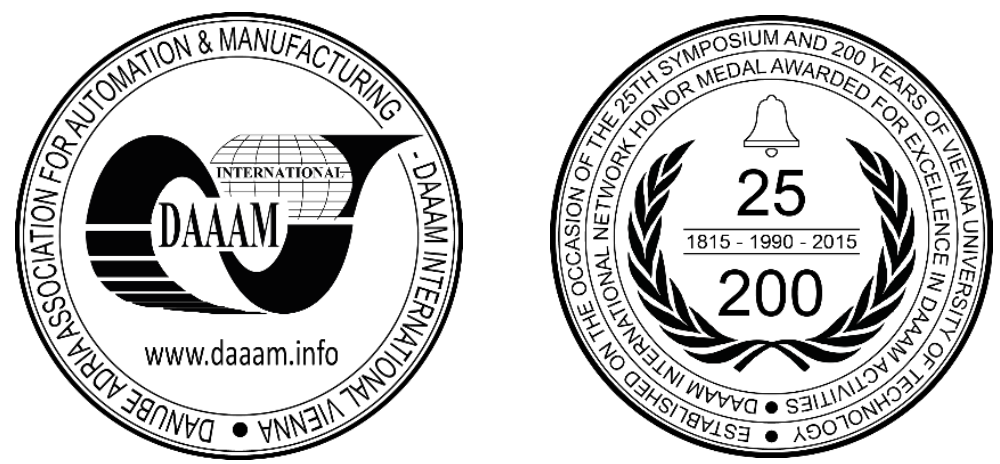

This Publication has to be referred as: Nozar, M[artin]; Zetkova, I[vana]; Hanzl, P[avel] \& Dana, M[ilan] (2017). A Customer's View on Key Aspects of Metal Additive Manufacturing, Proceedings of the 28th DAAAM International Symposium, pp.0957-0966, B. Katalinic (Ed.), Published by DAAAM International, ISBN 978-3-902734-11-2, ISSN 1726-9679, Vienna, Austria

DOI: $10.2507 / 28$ th.daaam.proceedings.133

\begin{abstract}
Additive technologies enable the creation of complex shapes and structures virtually unattainable using classical production processes. These technologies allow components to be produced not only from paper or plastic, but also from composite materials or metals, with the same or even better properties than their predecessors made by machining or forming technologies. However, for customers who are not specialists in these technologies it may often be difficult to orientate themselves in the wide range of options and take full advantage of the potential of these technologies. As a rule, production process parameters are not as decisive as final product characteristics, especially the price, quality and delivery date. Therefore, this article tries to answer elementary questions that customers might have when considering production using additive technology, and to describe its specifics and possibilities. Special attention is paid to metal 3D printing, whose specifics are illustrated using the example of printing a simple component in various ways, in different quantities and sizes. The article documents an experiment conducted under real conditions using DMLS technology, which shows how differences in ways of printing affect the price, the processing time, and the quality of the final component.
\end{abstract}

Keywords: Additive manufacturing; build orientation; processing time; build cost

\section{Introduction}

\subsection{Additive manufacturing}

Additive manufacturing (AM), also known as 3D printing, rapid manufacturing, additive fabrication, additive processes, additive techniques, additive layer manufacturing, layer manufacturing, and freeform fabrication is defined by the American Society for Testing and Materials (ASTM) [10] as "The process of joining materials to make objects from 3D model data, usually layer upon layer, as opposed to subtractive manufacturing methodologies". 
These technologies have witnessed intensive development in recent years and have found their applications not only in industrial and prototype manufacturing. Nonetheless, they are very specific and their production potential significantly differs from conventional production technologies. Although they can create very complicated shapes and structures which were previously almost impossible to manufacture, these technologies have their own limitations and are not capable of doing everything that a designer could invent. Specialists working with this technology are well aware of its capabilities and limitations, but for customers it could be quite difficult to properly consider its capabilities with respect to the required parameters and to correctly formulate their requirements. Because of this, they are often dependent on recommendations from specialists, who have to identify and formalize all the relevant data. However, in order to take complete advantage of the opportunities offered by the technology, it is necessary to know exactly what is manufacturable using this technology and what is not. For this purpose, this article tries to take a closer look at the options offered by additive manufacturing from a customer's point of view and to study the printing of one specific component, with emphasis on three important factors - price, quality and delivery date. Its motivation is to point out, with the help of a simple experiment, the differences from conventional manufacturing that may not be obvious but which could have a significant impact on the properties of the final product, and to answer questions that customers may have when considering the manufacture of a particular component using this technology. The experiment, in which several test prints and print simulations are carried out, clearly illustrates the differences in price, time and quality of identical components printed in different ways and in different sizes and quantities. In doing so, the key aspects of this technology are demonstrated here, and the question is answered whether higher quality always means higher costs in the additive production process, and to what extent cost-saving efforts could negatively affect the quality of the manufactured component.

\subsection{Advantages, limitations and key aspects of additive technologies}

Additive technologies in themselves have a number of advantages over conventional manufacturing methods. Among the most prominent is the possibility to design parts with unlimited complexity, allowing twisted and contorted shapes, variable wall thickness, blind holes and screws, and very high strength-to-weight ratio. And therefore, since the manufacturing of complex aesthetic shapes is no longer a problem, designers can focus on designing exceptional part functionality and assembly - additive technology allows several parts to be combined into an integrated assembly. [4] Moreover, additive technologies allow the true customization of every product - every single part, built at the same time, can have a different shape or size. And in doing so, there is no need for tooling development, so additive technologies make the production process faster by passing from design to production.

On the other hand, there are some drawbacks associated with these processes including high machine, material, and maintenance costs, slow production rate, limited build sizes, dimensional accuracy, and the small variety of materials available for processing. In comparison to conventional manufacturing, there are some unexpected downsides, which are generally based on a particular AM machine (i.e. its building method and parameters), and particular settings of the building process. A specific product's design, considering possible build problems and constraints, needs to be carefully analysed in order to achieve such optimal parameters for the production process [12].

In terms of quality, the most important aspects of a final product are its mechanical properties, dimensional and shape accuracy, and surface roughness. All of these aspects can be influenced by the correct setting of the processing parameters (for more details see e.g. [7]), above all with:

- Laser power and scanning speed on the structure of the material

- Hatch angle (the angle between laser scanning directions on individual layers)

- Building orientation (the acute angle between the longitudinal axis of a fabricated part and the vertical axis)

- Layer thickness

- Overlap rate (the amount of area which is influenced by repeated sintering with the energy beam)

While there is often no ideal combination of these parameters, it is always necessary to consider the following negative factors which decrease the quality of the final component:

- $\quad$ Staircase effect (a negative effect causing surface roughness to increase and degradation of dimensional accuracy due to orientation of the printed part on the platform)

- Volume shrinkage (risk of degradation of shape and dimensional accuracy caused by print settings)

- Heat dissipation (risk of possible deformation of printed parts due to laser heat transfer to surrounding material)

- Removability of support structures (hard to remove or impossible to remove supports, particularly of internal structures and cavities)

- Tension in material (presence of temperature gradient along the Z-axis of the part bed, which must be removed by subsequent heat treatment)

To a certain extent it is possible to influence all of these factors by suitable settings of the process parameters, but in the described experiment the setting of the layer thickness, the printed component orientation and creation of effective 
support structures are crucial (while maintaining the other parameters of the recommended settings). While the layer thickness could be set up as needed (according to the machine parameters), the support structures depend on the chosen orientation. However, the decision on a component's orientation has much more significant consequences. In addition to a component's mechanical properties (anisotropy), it influences the surface quality, processing time and costs. These aspects, which are particularly important and examined in this article, are influenced by the component orientation as follows [2]:

- The height of the part in the build direction, which is directly related to the total build time and hence final cost

- Total volume of support material used. The support structure does not contribute towards the finished part, wasting both build time and material

- Total area of contact of the part with the support structure. Reducing contact area decreases the time and the cost of removing supports and finishing surfaces

- The quality of selected faces (or total surface area) measured by surface accuracy. How a part is oriented determines which faces are subjected to the staircase effect and which are in contact with supports. Both these factors deteriorate the surface quality of the manufactured part

\section{Specifications and parameters of the experiment}

\subsection{Building technology}

The experiment described in this article was carried out using Direct Metal Laser Sintering (DMLS) technology. This technology is one of the major additive methods used to manufacture metal components. In a nutshell, this method operates as follows: A 3D model in "stl" format is redesigned as required (above all, any surface errors and inappropriate shapes are eliminated), support structures are generated, road paths are calculated and then the model is digitally cut into discrete slices. These slices are sent to the DMLS machine, which recombines them in a layer-by-layer sequence. The machine selectively scans the surface of the metal powder bed with a fibre laser, effectively creating a thin, planar slice of solid part geometry. Once the sintering of the layer is complete, a new specific increment of metal powder is deposited and the sintering of the next layer commences. This cycle is repeated until the build is complete [2].

\subsection{AM machine technical data}

An AM machine of type EOS M 290 was used for this experiment. This model has a building volume $250 \times 250$ x $325 \mathrm{~mm}$ and uses a $\mathrm{Yb}$ fibre laser with $400 \mathrm{~W}$ beam power, up to $7.0 \mathrm{~m} / \mathrm{s}$ scanning speed and $100 \mu \mathrm{m}$ focus diameter. EOS Maraging Steel MS1 (AKA 1.2709 or X3NiCoMoTi 18-9-5) with $8.0 \mathrm{~g} / \mathrm{cm}^{3}$ density was used as build material, and Argon was used as the protective atmosphere.

\subsection{Model component}

The model part selected for printing can be seen in Figure 1. This component in various orientations and quantities was used for several trial prints and simulations. The orientation of the component on the platform has a significant effect on building time, quality and the cost of the final part. The aim of the experiment is to compare 4 orientations to find the lowest cost, processing time and the best quality of the component.

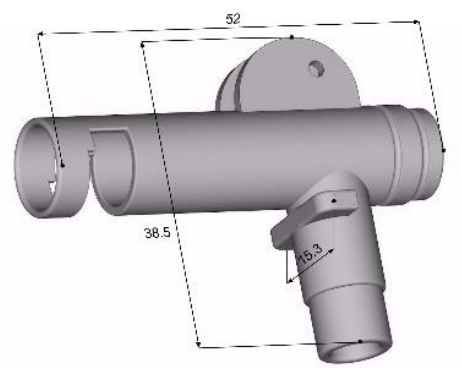

Fig. 1. Model component

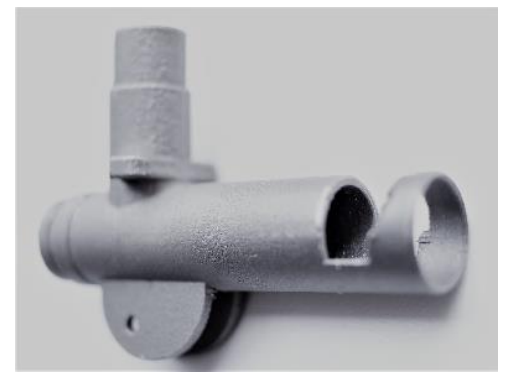

Fig. 2. Built component

For the comparison, the component was printed in 3 variants with 20 and $40 \mu \mathrm{m}$ layers and in different orientations (see Fig. 3) which have specific advantages and disadvantages. The basic variant was a printing simulation of a single component on the platform. The next, in order to take into account the effect of the size on detected values, was the simulated component print in the given orientations but with four times larger dimensions. And the last, due to the obvious high cost of printing single components, represented a print simulation of the maximum possible number of components on the platform (Fig. 4). 


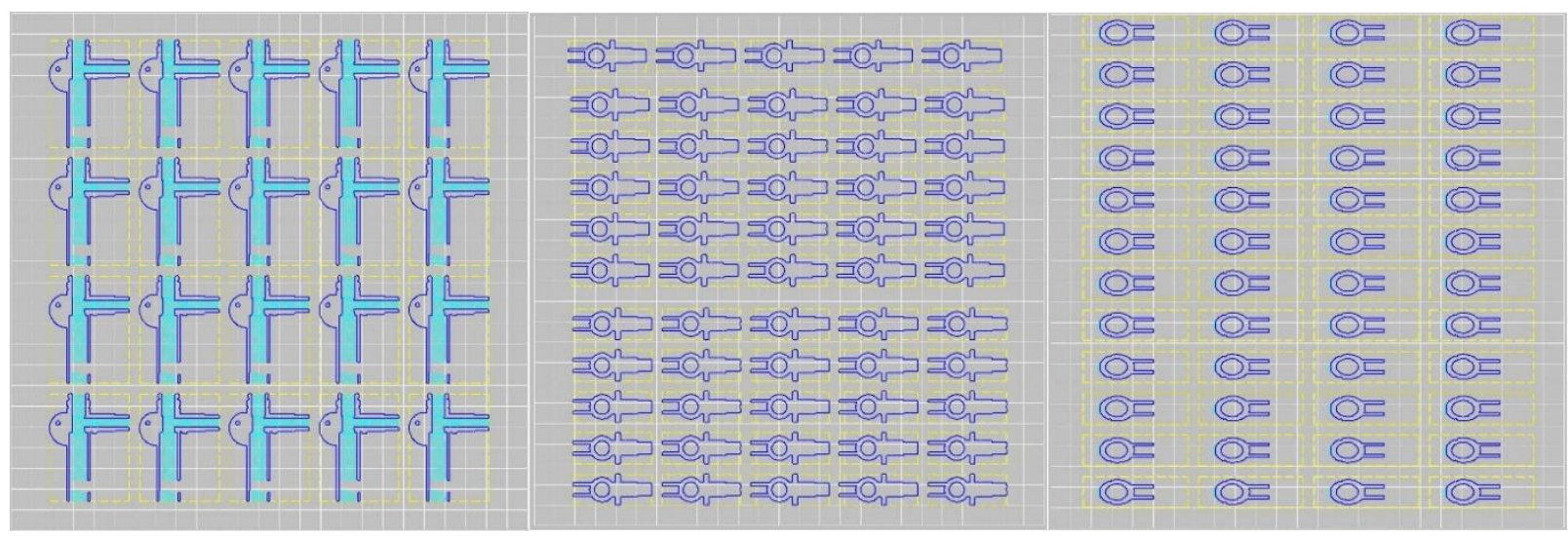

Fig. 3. - 5. Distribution of components on the platform

\section{Qualitative aspects}

\subsection{Build orientation and support structures}

Building orientation is a very important factor that affects the build process as well as the post-processing costs and mechanical properties. For instance, it causes anisotropy of the tensile properties of every fabricated part and therefore the placement and angle of rotation on the platform have to be chosen optimally according to the functionality of the part. Special attention must be paid to the fact that this direction also predetermines the number and volume of the support structures required.

The model component was printed in positions as shown in Fig. 6 - 9. The supports are shown in red. The volume of these components and their supports are given in Table 2. The supports were automatically generated by Materialize Magics software and adjusted as necessary.
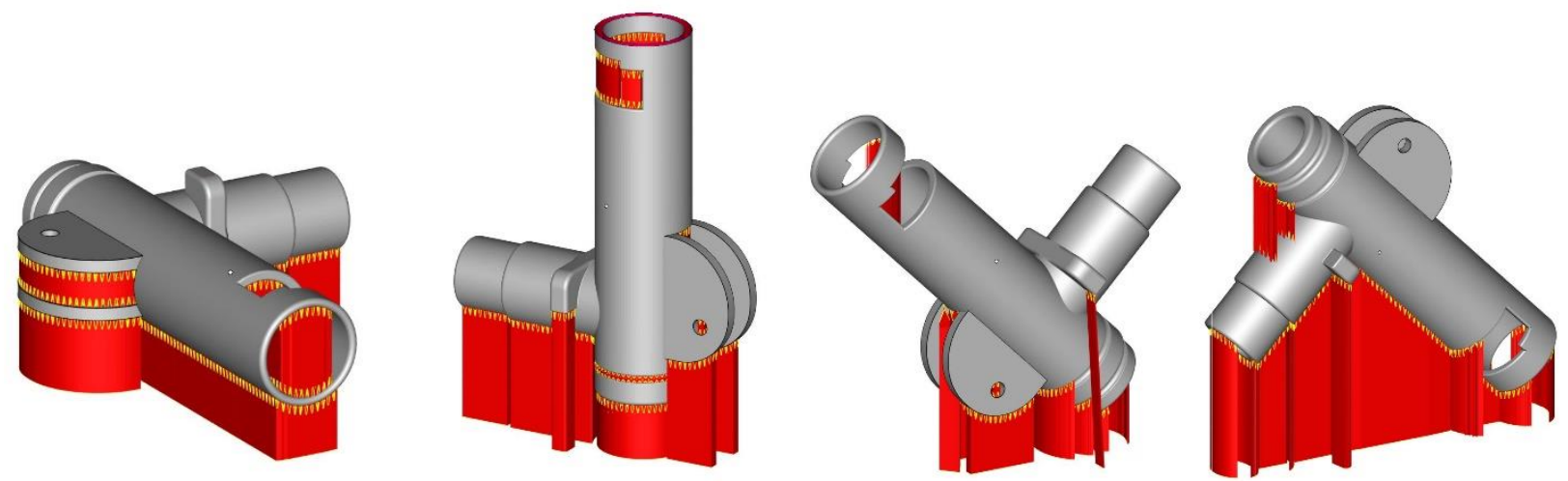

Fig. 6. - 9. Component orientations No. 1 - No. 4

The positons in Fig. 6. - 9. were chosen intentionally, above all with respect to the following principles of building orientation and support creation [2]:

- Minimizing the part's height (consistent with Orientation No. 1)

- Maximizing the stability of the object by selecting the largest base convex hull (consistent with Orientation No. 1)

- Minimizing the volume of the support to reduce excess time and cost of depositing and removing wasted material (consistent with Orientation No. 3)

- Minimizing total surface area of contact with the support to reduce support removal and finishing time (consistent with Orientation No. 3 and partly No. 4)

- Maximizing the surface accuracy of the part for better part quality, which will reduce the finishing time (consistent with Orientation No. 2).

\subsection{Quality evaluation of individual components}

As already mentioned, using the appropriate build orientation and support structures can significantly improve the quality of the part, because a major source of part inaccuracy and degraded surface properties are contacts with support structures and the staircase effect. 
Therefore, it is wise to minimize these factors as much as possible to avoid post-processing (grinding, polishing, etc.) operations. Unfortunately, meeting these requirements can be quite complicated because on the one hand functional areas should be oriented either horizontally or vertically to maximize surface accuracy, and on the other hand horizontal downfacing surfaces need to be supported, while vertical ones do not. This is exactly the main problem of orientations No. 3 and 4 in our experiment.

In the experiment, the parts were printed in $40 \mu \mathrm{m}$ and $20 \mu \mathrm{m}$ thin layers. As expected, the thinner layers were always of higher quality, but the printing time was roughly double, as can be seen from Table 1. A partial solution to this could be the option of setting individual layers, which enables different parameters to be used locally and depositing thinner layers only where necessary. Modern AM machines already have this functionality, which can improve surface properties, without increasing costs too much. In the case of the EOS M 290 printer, this is enabled by the latest EOS Print 2.0 software [9].

Orientation No. 1: This orientation is not very recommendable due to the great volume of the supports. These supports negatively affect the quality by contacting the printed components across a too large surface, even in the internal parts, from which it is relatively hard to remove them. Thus, the printed component will still have to be machined.

Orientation No. 2: This orientation shows a relatively small volume of supports, but unfortunately, some of them are internal. The main advantage of this orientation is the shape and dimensional accuracy. However, some internal and functional areas in the lower part of the component need to be machined.

Orientation No. 3: This orientation has the minimum volume of supports, which is achieved by rotation of the component, meaning that there is no need for internal supports (except for two tiny and easily removable internal supports). The main disadvantage is the degraded surface quality due to the staircase effect. For a component printed in this way, it is suitable to create it in $20 \mu \mathrm{m}$ layers or use some subsequent finishing operations.

Orientation No. 4: The component with this orientation has relatively extensive supports, but only external ones (except for one tiny and easily removable internal support), and provides the printed component with good stability and heat dissipation. Due to the large contact of the supports with the body of the component, subsequent finishing operations are required, as in Orientation No. 3.

\section{Time aspects}

\subsection{Processing times}

Many relevant studies [1], [3], [6] in accordance with observations from practice confirm that the manufacturing time per part is the key factor to optimizing the costs of additive manufacturing. The time spent on the whole building process consists of:

- $\quad$ Pre-processing time (model preparation, machine set-up, machine atmosphere generation, machine warm-up, etc.)

- Processing time (scanning time, Z-axis movement, levelling, non-manufacturing movement of the nozzle/laser, etc.)

- Post-processing time (cooling time, machine cleaning, unused powder sifting, sawing pieces from the platform, finishing operations such as heat treatment, milling, polishing, etc.)

In our experiment, we took into account only the processing time, since pre-processing times are practically the same for all positions, and the post-processing times differ primarily in the finishing operations required by a customer or by the function of the printed component. Generally, post-processing times can be reduced in various ways that are, however, different for each and every component, and therefore they have not been taken into consideration, neither have we considered time losses caused by possible failures or repairs of defective components.

A simulated print was performed to compare the print times of model components in different orientations - the prepared models were sent to the machine, which determined the exact printing times. The simulated print was made for variants with single component printing, enlarged component printing, and print of multiple components with original size. In this variant, the building platform was completely filled with components so the part in Orientation No. 1 was printed 20 times, 55 times in Orientation No. 2, and 48 times in Orientations No. 3 and 4. See Fig. 6. - 9.

Processing times of the model component in the different orientations and variants are given in Table 1.

\begin{tabular}{|c|c|c|c|c|c|c|c|c|}
\hline \multirow{3}{*}{$\begin{array}{c}\text { Component } \\
\text { type }\end{array}$} & \multicolumn{8}{|c|}{ Processing Times in different Orientations (min.) } \\
\hline & \multicolumn{2}{|c|}{ No. 1} & \multicolumn{2}{|c|}{ No. 2} & \multicolumn{2}{|c|}{ No. 3} & \multicolumn{2}{|c|}{ No. 4} \\
\hline & layer $20 \mu \mathrm{m}$ & layer $40 \mu \mathrm{m}$ & layer $20 \mu \mathrm{m}$ & layer $40 \mu \mathrm{m}$ & layer20 $\mu \mathrm{m}$ & layer $40 \mu \mathrm{m}$ & layer20 $\mu \mathrm{m}$ & layer $40 \mu \mathrm{m}$ \\
\hline Single & 239 & 120 & 537 & 241 & 466 & 218 & 478 & 224 \\
\hline Multiple & 1666 & 1037 & 3969 & 2025 & 2887 & 1976 & 3661 & 2300 \\
\hline Large & 4349 & 2346 & 5158 & 2206 & 4352 & 2195 & 4798 & 2440 \\
\hline
\end{tabular}

Table 1. Print Times (in minutes) 


\subsection{Evaluation of component processing times}

As shown in Table 1., the fastest possible print of the component can be achieved in Orientation No. 1. when applying $40 \mu \mathrm{m}$ thin layers. In contrast, when applying $20 \mu \mathrm{m}$ thin layers in Orientation No. 2, the print is almost four times longer, due to the largest building size of the component in this orientation. This is also the reason why the time values for orientations No. 3 and 4 are quite similar, since the components have the same building height. Observable differences are only caused by the difference in support print times, and these are more massive in Orientation No. 4.

In general, printing using $20 \mu \mathrm{m}$ thin layers is roughly two times longer than for $40 \mu \mathrm{m}$ layers. A big difference is evident between the time of printing the original and the enlarged component, which is 4 times higher, but the print time is 6-10 times longer. This disproportion is caused not only by the printing of a greater volume, but above all by the significant building height, which means many more deposited layers, and hence more time spent on the recoating procedures.

\section{Price aspects}

\subsection{Costing estimation for additive manufacturing}

There are several approaches to determining the cost model of component production using AM. It is possible to use the model below as an example [1]. The highlighted costs are important for the following calculations and the printing cost evaluations.

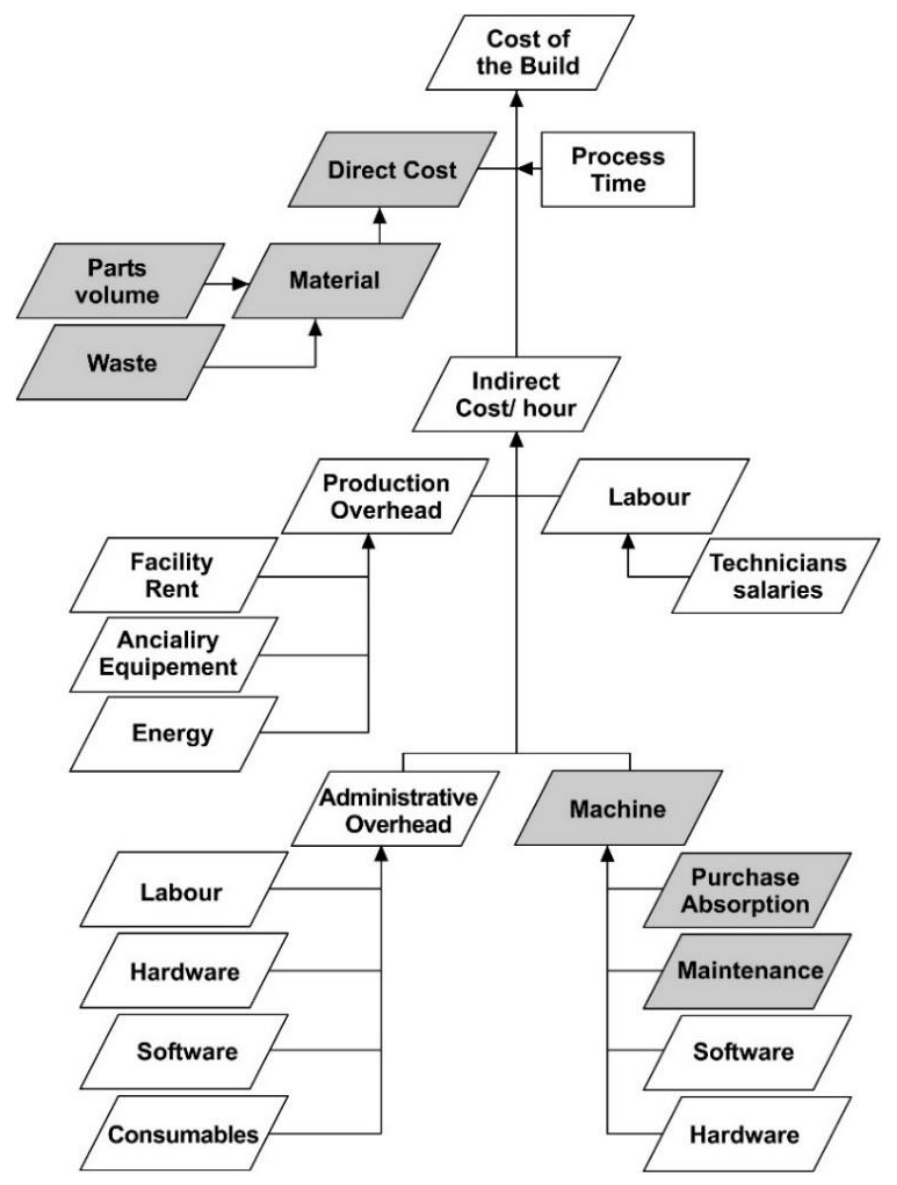

Fig. 10. Diagram of the costing model [1]

\subsection{Structure of the processing costs}

It is possible to find these with economic (or cost) models (e.g. the model above) and the prices of particular components in various publications (e.g. [1], [5]). However, this article is not concerned with determining the total cost or price of printing, just costs that are directly related to the printing of the model components in the given orientations. For the purpose of costs quantification real and current prices were used, which are not stated in detail in this article, because these calculated costs, no matter how thoroughly they were identified, have only relative informative value and they are stated here just for the possibility of making different options and comparing orientations. 
It is not possible to compare these costs with the cost of manufacturing using a different AM machine as material prices depend on the time when the calculation was made, on the country where the survey is conducted and the current exchange rate (this calculation was made with prices valid in the Czech Republic in September 2017 and in Czech Crowns). Further differences in the calculation may be caused by the selected (or required) material, which may have different processing properties and parameters.

Using a different printer could also cause significant differences, as it may have different production capabilities. For example, a printer could have a significantly larger workspace (i.e. multiple components can be printed concurrently), it could be a hybrid AM machine (i.e. capable of machining printed shapes during a printing process) or a multi-laser machine (usually using 4 lasers to shorten the processing time), or a printer could be equipped with a sieving module (to shorten times of powder recycling and to reduce powder material losses). However, all these benefits mean increased investment costs for the acquisition of the AM machine and its appropriate equipment.

Very significant differences in values can also be obtained if we take into consideration the operator's capabilities and the equipment's operating conditions, in particular the service lifetime and worktime fund of a given AM machine. In the case of the AM machine used in this article, its user is a university research centre, which uses this AM machine for research and prototype development. This means a larger portion of pre-processing time, shorter working hours and potentially longer service lifetime than printers used for commercial production. All this is reflected in the hourly machine rate, which is based on the purchase price and the depreciation method of the AM machine. That is why there are almost no absolute sums here, as they virtually would not be predictive.

To complement this topic, we recommend an article [1] in which the authors made a cost calculation based on $60 \%$ utilization of the machine time fund in 8 years, i.e. at the limit recommended by the machine manufacturer. A study [8] from 2016 is also very interesting and relevant, in which its author compared three different AM systems (including the EOS M 290) and stated the hourly machine rates with proportions of their individual components. Considering a 5-year depreciation period, utilization $5000 \mathrm{~h}$ p.a., $10 \%$ maintenance and downtime, the hourly machine rates (include only processing time, i.e. without material and direct labour costs), range from 35 - $45 \mathrm{EUR} / \mathrm{h}$ for a 'small single-laser' machine to 90 - $120 \mathrm{EUR} / \mathrm{h}$ for a 'large machine'.

\subsection{Relevant costs calculation}

Calculated costs considered in our experiment include material costs (energy and gas) and processing costs (which result from processing time, so they include machine depreciation and regular maintenance costs). The consumption of metal powder is calculated according to the volumes of the printed components and their respective support structures. Both these volumes are stated in Table 2.

\begin{tabular}{|c|c|c|c|c|c|c|c|c|}
\hline \multirow{2}{*}{$\begin{array}{c}\text { Component } \\
\text { type }\end{array}$} & \multicolumn{9}{|c|}{ No. 1 } & \multicolumn{2}{|c|}{ No. 2 } & \multicolumn{2}{c|}{ No. 3 } & \multicolumn{2}{c|}{ No. 4 } \\
\cline { 2 - 9 } & Component & Support & Component & Support & Component & Support & Component & Support \\
\hline Single & $\mathbf{3 4 2 2}$ & 7665 & $\mathbf{3 4 2 2}$ & 3146 & $\mathbf{3 4 2 2}$ & 903 & $\mathbf{3 4 2 2}$ & 3840 \\
\hline Multiple & $\mathbf{6 8 4 4 0}$ & 153302 & $\mathbf{1 8 8 ~ 2 1 0}$ & 173003 & $\mathbf{1 6 4 2 5 6}$ & 43351 & $\mathbf{1 6 4 2 5 6}$ & 184344 \\
\hline Large & $\mathbf{2 1 9 0 0 2}$ & 348825 & $\mathbf{2 1 9 0 0 2}$ & 144872 & $\mathbf{2 1 9 0 0 2}$ & 29642 & $\mathbf{2 1 9 0 0 2}$ & 158356 \\
\hline
\end{tabular}

Table 2. Volumes of printed components and their support structures (in $\mathrm{mm}^{3}$ )

It is necessary to add the volumes of metal power depreciated and lost during processing and post-processing operations and which cannot be reused, to the volumes stated in Table 2.. According to the producer, 2- $4 \%$ of the powder material is considered waste.

However, according to our own measurements (accurate material weighing before and after printing), EOS MS1 metal powder losses reach up to $25 \%$ of the printed component's volume. Therefore, this amount of metal powder was added into the calculated consumption. The consumption of electric power (above all of the printer and compressor) and gas (e.g. Argon; to create a protective atmosphere) was also put into the calculation.

This calculation revealed (in accordance with some previous studies [1], [4]), the major part of the cost is found to be due to investment in the machine and regular maintenance costs. The costs of energy and materials only contribute to a small extent. The sum of costs $\left(\mathrm{C}_{\Sigma}\right)$ and share of processing $\operatorname{cost}\left(\mathrm{C}_{\mathrm{pt}}\right)$ for all simulated orientations and variants are shown in Table 3. The sums of costs are stated in Euros (recalculated with current exchange rate 26 EUR/CZE). Note: $\mathrm{Q}_{\max }$ is the maximum number of components on the platform. 


\begin{tabular}{|c|c|c|c|c|c|c|c|c|c|c|c|c|}
\hline \multirow{3}{*}{ Orientation } & \multicolumn{4}{|c|}{ Single } & \multicolumn{4}{|c|}{ One of $Q_{\max }$} & \multicolumn{4}{|c|}{ Large } \\
\hline & \multicolumn{2}{|c|}{ layer $20 \mu \mathrm{m}$} & \multicolumn{2}{|c|}{ layer $40 \mu \mathrm{m}$} & \multicolumn{2}{|c|}{ layer $20 \mu \mathrm{m}$} & \multicolumn{2}{|c|}{ layer $40 \mu \mathrm{m}$} & \multicolumn{2}{|c|}{ layer $_{20 \mu \mathrm{m}}$} & \multicolumn{2}{|c|}{ layer $_{40 \mu \mathrm{m}}$} \\
\hline & $\mathrm{C}_{\Sigma}$ & $\mathbf{C}_{\mathrm{pt}} / \mathbf{C}_{\Sigma}$ & $\mathrm{C}_{\Sigma}$ & $\mathbf{C}_{\mathrm{pt}} / \mathbf{C}_{\Sigma}$ & $\mathbf{C}_{\Sigma}$ & $\mathbf{C}_{\mathrm{pt}} / \mathbf{C}_{\mathbf{\Sigma}}$ & $\mathrm{C}_{\Sigma}$ & $\mathrm{C}_{\mathrm{pt}} / \mathbf{C}_{\mathbf{\Sigma}}$ & $\mathrm{C}_{\Sigma}$ & $\mathbf{C}_{\mathrm{pt}} / \mathbf{C}_{\Sigma}$ & $\mathrm{C}_{\Sigma}$ & $\mathbf{C}_{\mathrm{pt}} / \mathbf{C}_{\Sigma}$ \\
\hline No. 1 & 172 & $92 \%$ & 94 & $85 \%$ & 69 & $80 \%$ & 48 & $71 \%$ & 3615 & $80 \%$ & 2289 & $68 \%$ \\
\hline No. 2 & 364 & $98 \%$ & 168 & $95 \%$ & 57 & $84 \%$ & 33 & $74 \%$ & 3909 & $87 \%$ & 1955 & 75\% \\
\hline No. 3 & 315 & $98 \%$ & 150 & $96 \%$ & 46 & $87 \%$ & 33 & $82 \%$ & 3239 & $89 \%$ & 1811 & $80 \%$ \\
\hline No. 4 & 326 & $97 \%$ & 158 & $94 \%$ & 60 & $84 \%$ & 41 & $77 \%$ & 3687 & $86 \%$ & 2126 & $76 \%$ \\
\hline
\end{tabular}

Table 3. Sum of costs (in EUR) and share of processing costs in them

\subsection{Evaluation of variants}

As outlined in Table 3., when printing single components, the cheapest component is printed in Orientation No. 1, with no difference when printing in 20 or $40 \mu \mathrm{m}$ thin layers. In other cases, the cheapest printing is in orientation No. 3 , with the exception of printing with a maximum number of components in $40 \mu \mathrm{m}$ thin layers, where costs are even slightly lower. The values given above also indicate how beneficial the horizontal filling of an AM machine working space is. The greatest savings are thus obtained when printing in $20 \mu \mathrm{m}$ thin layers (on average 78\%), especially in orientations No.2 (84\%) and No.3 (85\%). As expected, printing in $20 \mu \mathrm{m}$ layers is always more expensive; for single component print variants on average twice as expensive, for multiple component print variants 1.5 times as expensive, and for large print variants 1.7 times as expensive.

This table also shows that the decisive factor in the calculated costs is the processing cost (in another words machine investment cost), which reaches on average 94\% (for all orientations and both layer thicknesses) during single component printing. This value does not fall below $80 \%$ on average, even in the cost calculation of the multiple component print when the total cost is distributed per piece, or in the cost calculation of the enlarged component print. Even when considering the maximum recommended machine utilization, as used in the article [4], the average percentages of processing costs do not fall below $88 \%$ in single print variants and below $64 \%$ in large and multiple print variants. In this case, the total lowest values were reached by printing on a full platform with components in orientations No. 1 and No. 2. However, the percentage values exceed 52\% here as well. Therefore, it is clear that there is no print variant where the processing costs would not be the decisive part of print costs.

As a result, it is possible to state that in terms of price, the volume of the support structures is not a decisive factor (unless such support structures require complicated and costly removal), and filling the available AM machine build space is the prime determinant for the efficient operation of the technology.

\section{Evaluation of experiment results}

The purpose of the experiment was to evaluate the printing of a model component in various orientations and three different variants which were simulated by AM machine. The evaluation was carried out with regard to quality, processing time and cost. At the end, the component was printed in order to confirm all our conclusions.

As it turned out during the evaluation, it is not possible to find an ideal component orientation when taking into account the aspect of quality - each orientation has its own advantages and disadvantages, and it is a matter of individual assessment to determine which of these factors are less problematic for the customer and the function of the printed component. A qualitative aspect is therefore useful purely as a guide. A quite similar case is also the time aspect where the component orientation is not decisive, unlike the size of the printed volume. However, processing time is a determining factor for processing costs, which, as has been shown, creates the main part of the printing costs.

In terms of time, orientation No. 1, which has the smallest building height and therefore the smallest number of printed layers, would be the ideal case. Unfortunately, this variant is not the most cost-effective option (it is most cost-effective only when printing a single component, which is the least economical variant) and, moreover, a high volume of internal and external support structures require a large number of finishing operations which increase production time and costs. The disadvantage of this orientation is also the fact that when printing more components at the same time, this component can be placed in the smallest quantity (20 copies) on the building platform. Therefore, when printing a large number of components in this orientation, this printing option ceases to be favourable in both cost and time.

As expected, it reveals the key aspect to be the price, implicitly including the time aspect. Thus, if we prefer the price aspect, it seems orientation No. 3 is the most favourable one in most cases. However, in this case it is necessary to take into account the deteriorated surface quality due to the staircase effect. This can be partially avoided by printing this component in $20 \mu \mathrm{m}$ thin layers, which means an increase in costs of $40 \%$.

In this context, it is necessary to draw attention to the possible instability of this component during printing due to the small number of support structures that could cause printing defects. Because of this risk the component in orientation No. 4 is equipped with more massive support structures. 
These support structures increase the processing costs on average by $16 \%$, but provide the printed component with greater stability and better heat transfer from the laser beam into the surrounding material. However, a component oriented in this way is also liable to suffer a deterioration in surface quality due to the staircase effect.

This undesirable effect has almost no impact on the component in orientation No. 2, which is oriented perpendicularly to the building platform, and thus attains the highest quality in shape and size. A component printed in this orientation is one of the most expensive ones in most cases, but it is possible to print it in the largest number of copies (55 copies) concurrently, but when printing even with a full building platform, the price per component exceeds even the cheapest orientation No. 3. In contrast to this orientation, it has the advantage of having a good surface even when printed in 40 $\mu \mathrm{m}$ thin layers, but the disadvantage is that there are internal support structures at the bottom of the component, which need to be removed.

When considering time and cost, it is quite easy to identify the optimum orientation in given circumstances. Unfortunately, in the case of quality the situation is much more complicated because each orientation has its pros and cons. And insufficient quality could mean repeated printing, which doubles its original price. Therefore, for practical printing it is advisable (due to the significant disparity between material and processing costs) to print the component with a more massive but safer support structure (unless it could cause complications during its removal), to carry out a test print, e.g. add this component to a different print batch in order to verify its properties, or to print this component in several efficient orientations concurrently. There are several approaches to manufacturing a suitable component, but when seeking the best one it is always necessary to know whether quality (i.e. functional properties), time or costs matter the most.

\section{Conclusion}

This article is dedicated to metal additive manufacturing, which uses a laser beam to melt metal powder to form solid objects. Basic aspects of this technology are presented, its capabilities and limitations that need to be taken into account when considering manufacturing using laser sintering. The article explains that it is not enough just to solve whether the required piece or component can be printed at all, but also the importance of the orientation of this component during printing. From the customer's point of view it is essential to what extent just this orientation directly affects the quality (surface and mechanical properties), processing time and processing cost. Therefore, this article attempts to give answers to the basic questions regarding which factors affect price, quality and processing time; how to save costs without compromising quality; and whether higher cost and longer processing time always result in better quality. At present, there is some software capable of optimising the arrangement and orientation of parts on the platform, but it only provides recommendations made with regard to appropriate criteria. But as demonstrated in the article, as a rule, every single orientation has its positive and negative aspects, so the final decision about the build orientation is always up to the specialist/customer who has to thoroughly assess the specific situation.

For the purpose of comparison of different building orientations on the platform, i.e. above all for finding the connection between quality, costs and building time, we prepared different printing models, created a calculation formula, quantified cost components and simulated printing of these models. The values we obtained enabled us to compare and evaluate all the orientations and variants from the customer's perspective.

The experiment was carried out on an EOS M 290 machine and based on printing a selected component in four different orientations, quantities and sizes; and the values obtained from each of the simulations were recorded into 3 tables for cross-referencing. As it turned out, when the results were evaluated with regards to quality, time and cost, every orientation and print variant has its own specific advantages and complications, so when deciding on individual print adjustments (not just the number and orientation of components), the key question is always whether to prefer quality (i.e. properties), time or price of these components. Sometimes the solution is unambiguous, but in a number of cases it is, unfortunately, a matter of compromise. However, since the processing time is the largest price factor, all measures to reduce the time also reduce the cost accordingly. As a result, additive technology users should fill the available build space with as many parts as possible because the manufacturing time per part is the key factor to optimizing the costs of additive manufacturing.

This article describes the issue from the perspective of the customer, who is primarily interested in quality, costs and printing time of the required component. However, this issue is more complicated and subsequent research will be conducted in two principal directions. On the one hand, the complete cost formula will be specified (i.e. all parts of the cost model on Fig. 10 will be considered) and a precise formula for building time calculation will be created (all the time values stated in this article were individually indicated by the machine). These formulas will enable us to create a special computer programme able to calculate and recommend optimum placements and building orientations of every piece by using advanced simulations and genetic algorithms. The orientations considered in this article are intentionally chosen to point out the differences between these de facto extremely different building directions, however, it is probable that the best option in many cases would be a combination of these orientations. Although it is possible to use a computer simulation to find such a combination, it requires a clearly and precisely determined criterion function, i.e. exact values of key parameters and their connections with processing parameters. Therefore, parallel research will investigate the impact of all the processing parameters on costs, quality and building time. 


\section{Acknowledgments}

The article has been prepared under project LO1502 'Development of the Regional Technological Institute' under the auspices of the National Sustainability Programme I of the Ministry of Education of the Czech Republic aimed at supporting research, experimental development and innovation.

\section{References}

[1] Ruffo, M.; Tuck, C.; Hague, R. (2006). Cost estimation for rapid manufacturing - laser sintering production for low to medium volumes, Available from: https://www.researchgate.net/publication/48352741_Cost_estimation_ for_rapid_ma-nufacturing_-_Laser_sintering_production_for_low_to_medium_volumes, Accessed: 2017-09-01

[2] Alexander, P.; Allen, S.; Dutta, D. (1998). Part orientation and build cost determination in layered manufacturing. Available from: http://www.sciencedirect.com/science/article/pii/S0010448597000833, Accessed: 2017-09-01

[3] Piili, H.; Happonen, A.; Väistö, T.; Venkataramanan, V.; Partanen, J.; Salminen, A.;(2015). Cost Estimation of Laser Additive Manufacturing of Stainless Steel, Available from: http://www.sciencedirect.com/science/article/pii/S1875389215015436, Accessed: 2017-09-01

[4] Atzeni, E.; Salmi, A.; (2012). Economics of additive manufacturing for end-usable metal parts. Available from: https://link.springer.com/content/pdf/10.1007\%2Fs00170-011-3878-1.pdf, Accessed: 2017-09-01

[5] Baumers, P.; Tuck, C.; Hague, R.; (2016). The cost of additive manufacturing: machine productivity, economies of scale and technology-push, Available from: http://www.sciencedirect.com/science/article/pii/S0040162515000530, Accessed: 2017-09-01

[6] Baumers, M.; Tuck, C.; Wildman, R.; Ashcroft, I.; Rosamond, E.; Hague, R.; (2012). Combined Build-Time, Energy Consumption and Cost Estimation for Direct Metal Laser Sintering, Available from: http://citeseerx.ist.psu.edu/viewdoc/download?doi=10.1.1.476.5195\&rep=rep1\&type=pdf, Accessed: 2017-09-01

[7] Hanzl, P.; Zetek, M.; Bakša, T.; Kroupa, T. (2015). The Influence of Processing Parameters on the Mechanical Properties of SLM Parts, Available from: http://www.sciencedirect.com/science/article/pii/S1877705815005378, Accessed: 2017-09-01

[8] Berger, R. (2010). Additive Manufacturing - next generation, Available from: https://www.rolandberger.com/publications/publication_pdf/roland_berger_additive_manufacturing_next_generation_amnx_study_2016 0412.pdf, Accessed: 2017-09-01

[9] https://www.eos.info/systems_solutions/software/eosprint, (2017). EOS, EOSPRINT 2.0, Accessed: 2017-09-23

[10] https://www.astm.org/Standards/F2792 (2017). ASTM, Standard terminology for additive manufacturing, Accessed: 2017-09-01

[11] Ruffo, M.; Hague, R. (2007). Cost estimation for rapid manufacturing - simultaneous production of mixed components using laser sintering, Available from: https://dspace.lboro.ac.uk/dspace-jspui/bitstream/2134/4808/1/ruffo2. pdf, Accessed: 2017-09-01

[12] Cekic, A.; Rasovic, N.; Obad, M.; Kaljun, J.; Dolsek, B.\& Begic-Hajdarevic, D. (2016). Production of Optimized Layered Products using Intelligent Support, Proceedings of the 26th DAAAM International Symposium, pp.02710279, B. Katalinic (Ed.), Published by DAAAM International, ISBN 978-3-902734-07-5, ISSN 1726-9679, Vienna, Austria DOI:10.2507/26th.daaam.proceedings.037 